\title{
The Challenge of Distributing Regulatory Responsibilities for Unknown Risks: 'Nano'-Cosmetics and the EU Cosmetics Regulation as a Case Study
}

Clare Shelley-Egan ${ }^{1^{*}}$ and Diana Megan Bowman ${ }^{2}$

${ }^{1}$ Trilateral Research \& Consulting, London, UK

${ }^{2}$ Health Management and Policy and the Risk Science Center, School of Public Health, The University of Michigan, USA

"Corresponding author: Clare Shelley-Egan, Trilateral Research \& Consulting, Crown House, 72 Hammersmith Road, W14 8TH, London, United Kingdom, Tel: 0031681591963; E-mail: clare.shelleyegan@gmail.com

Received date: November 21, 2014, Accepted date: February 06, 2015, Published date: February 16, 2015

Copyright: (c) 2015 Shelley-Egan C, et al. This is an open-access article distributed under the terms of the Creative Commons Attribution License, which permits unrestricted use, distribution, and reproduction in any medium, provided the original author and source are credited.

\begin{abstract}
The adoption of the European Union's (EU) Cosmetics Regulation-which came into effect as of July 2013-is significant because it was the first piece of legislation at the national or supranational level to include provisions relating specifically to the use of nanomaterials in any products. While the regulation does not change the fundamental aspects of the regulatory regime, which includes putting full responsibility for ensuring the safety of the cosmetic product on the manufacturer/importer, the provision of consumer labelling of nanomaterials suggests a shifting of responsibilities that is new for cosmetics within the EU market. Although this additional shifting of responsibilities is subtle, we argue that it is nonetheless problematic, given current uncertainties about what a 'nano label' actually means, in addition to doubts around the capacity to furnish the consumer with sufficient information to enable them to make a fully informed consumer choice. The aim of this article is to understand the challenge of distributing regulatory responsibilities for unknown or unquantified risks through the lens of the Cosmetics Regulation. We present and discuss data gathered in interviews with a small number of cosmetics stakeholdersincluding industry, representatives of government/regulatory agencies, NGOs/civil society and experts (in industry and dialogue)-as a means of illustrating various elements viewed by stakeholders as necessary to be able to take up responsibilities and identifying the constraining factors to doing so, i.e. regulatory challenges. The overarching aim of the article is to understand the implications of the distribution of responsibilities, as set out by the regulation, for enabling consumers to meaningfully differentiate between conventional cosmetic products and those containing nanomaterials.
\end{abstract}

Keywords: Cosmetics; Regulation; Distribution of regulatory responsibilities; Informed consumer choice; Labelling

\section{Introduction}

Shampoo, sunscreens and moisturisers. Each a cosmetic product, and products that we-or at least many of us-encounter each day. Being cosmetic products, there is an implied presumption that such products are safe; that we, as consumers, do not need to undertake a cost-benefit analysis each and every time we choose such a cosmetic product. The very fact that they are cosmetics products suggests that such 'risks' do not exist (or, are at least negligible in nature).

Entry into force of the European Union's (EU) new regulatory regime for cosmetic products-which are broadly defined with reference to their area of application on the body and the purpose for which they are applied ${ }^{1}$-occurred in July 2013. At that time, the Cosmetics Regulation (Regulation (EC) No 1223/2009) replaces the Cosmetics Directive, and in doing so, among other things, streamlines human safety requirements, increases transparency and harmonisation within the market and reduces the regulatory burden in relation to cosmetic products. This shall be achieved under the regulation by ensuring that consumers' health is protected and that consumers are well informed by monitoring the composition and labelling of products.

The adoption of the regulation by the European Parliament and Council in November 2009 represents yet another significant step forward in the EU's broader regulatory reform agenda. Yet the passage of this piece of legislation has significance beyond the EU; upon its passage, the Cosmetics Regulation became the first piece of legislation at the national or supranational level to specifically incorporate provisions relating specifically to the use of nanomaterials-as defined in the regulation-in any products [1-3]. ${ }^{2}$ While other jurisdictions continue to debate the merits of, or need for, such action, the passage of the legislation by the EU can be viewed as both significant and symbolic.

1 Article 2 in the regulation defines a 'cosmetic product' as "any substance or mixture intended to be placed in contact with the external parts of the human body (epidermis, hair system, nails, lips and external genital organs) or with the teeth and the mucous membranes of the oral cavity with a view exclusively or mainly to cleaning them, perfuming them, changing their appearance, protecting them, keeping them in good condition or correcting body odours".

2 New Zealand has subsequently adopted labelling requirements for cosmetics containing nanomaterials as set out in the Cosmetic Products Group Standard 2006 (CPGS) (HSNO Approval No. HSR002552) (pursuant to section 96B Hazardous Substances and New Organisms Act 1996 (HSNO Act)). As of 1 July 2015, cosmetic products containing nanomaterials within the New Zealand market will need to be labelled as such (see $[4,5]$ for more details). 
The adoption of the Cosmetics Regulation is also important because it provides a legislative instrument through which the challenge of distributing regulatory responsibilities for unknown risks may be explored. On the one hand, the regulation does not change the fundamental aspects of the regulatory regime, which include putting full responsibility for ensuring the safety of the cosmetic product on the manufacturer/importer. On the other hand, however, even a cursory review of the instrument illustrates the complexities of the obligations set out in its text when one considers the introduction of nano-specific provisions to the regulatory arrangement. Specifically, the provision of consumer labelling of nanomaterials suggests a shifting of responsibilities that is new for cosmetics within the EU market. This concept of shifting responsibilities is not new to the European Parliament or Council, having been a hallmark of the $\mathrm{REACH}$ regulation that was adopted by the Parliament in December 2006 (EC 1907/2006). ${ }^{3}$

The additional layer of responsibilities set out in the Cosmetic Regulation, which could be seen as a further subtle shift in the allocation of responsibilities, is arguably less extreme and less visible at this time. Pursuant to its text, where a cosmetic product contains nanomaterials-as defined in the regulation itself-a labelling requirement is triggered Article 19(1)(g). The manufacturer is 'only' responsible for indicating the presence of nanomaterial(s) in the list of ingredients. The label therefore provides information to the consumer about the size of some ingredients in the product; i.e. which ingredients are present in a nano-form, and by default, which are not. Compliance is, in part, dependent on the ability of industry to accurately characterize the ingredients as nanomaterials. The purpose of the label, as required under Article 19, is to inform consumers about the presence of nanomaterials in the product.

The label does not, however, provide information about the state of the science or the appropriateness of conventional risk assessment protocols for certain types of nanomaterials. Moreover, the manufacturer is not required to provide any indication regarding the risks (if any) or purported benefits of the ingredient. This is not the intention of the labelling requirement. Thus, given the considerations just mentioned, it would appear that, in their decision to purchase or not to purchase a product containing the nano label, consumers must engage in a decision-making process-which may be based in part on values and/or science-which is subsequently underpinned by a scientific risk assessment process. Throne-Holst et al. [6] make this assertion more strongly, arguing that the wider assessment of potential risks and benefits, and the overall desirability of nanomaterials, is left with the consumer. This subtle shifting of responsibilities is, in our view, problematic given current uncertainties about what a 'nano label' actually means, and doubts around the capacity to furnish the consumer with sufficient information to allow them to make a fully informed decision about the product in question [7].

The aim of this article is to understand the challenge of distributing regulatory responsibilities for unknown or unquantified risks-if indeed such risks exist at all-through the lens of the regulation of cosmetics products in the EU from July 2013 forward. Our primary focus is on both the labelling mechanism and catalogue of nanomaterials to be made publically available by the European
Commission (EC) as two forms of information disclosure, since they imply a new shifting of responsibilities for cosmetics. In order to understand the nature of the challenge of distributing responsibilities for unknown risks, we draw out the distribution of responsibility for unknown risks in terms of the provision of information down the value chain (regulatory authorities-manufacturers/importersconsumers) in various forms under the new regime. Our focus is on the requirements of regulatory authorities, the information and data obligations of downstream users such as manufacturers/importers and the provision and communication of information to downstream actors such as consumers.

In order to map the challenges faced by the different actors across the value chain, we take a multi-pronged approach. First, we offer an overview of the state-of-the-art regarding the use of nanomaterials in cosmetics within the EU market, differentiating between different types of nanomaterials being utilised within these products, and the potential benefits and/or risks associated with the different families of nanomaterials. Attention is focused on gaps in knowledge and inappropriate risk assessment methodologies, and drawing out the implications of the definition of nanomaterials as provided for in the regulation. Second, we provide an overview of the new regulatory framework for cosmetics. Third, we present and discuss interviews carried out with a small number of nano-cosmetics stakeholdersincluding industry, representatives of government/regulatory agencies and NGOs/civil society-as a means of illustrating various elements viewed by stakeholders as necessary to be able to take up responsibilities and identifying the constraining factors to doing so, i.e. regulatory challenges. By drawing these two lines of inquiry together, the overarching aim of the article is to understand the implications of the distribution of responsibilities, as set out by the regulation, for enabling consumers to meaningfully differentiate between conventional cosmetic products and those that contain nanomaterials.

\section{Nanomaterials in Cosmetics: A Well-hidden Ingredient until Now}

The cosmetics industry has always sought to innovate. As such, it is not surprising that the industry was one of the first to incorporate nanomaterials into a range of consumer products [8,9]. It would appear that nanomaterials were seen by industry as a way to enhance the properties of existing products, thereby increasing consumer demand and market share. Yet, despite the reported widespread use of nanomaterials in cosmetics, in the absence of mandatory product labelling requirements in any jurisdiction, and only limited selfidentification, it is as yet unclear how and where nanomaterials are being used in cosmetics [10].

The primary function of cosmetics is the maintenance of good appearance, changing the appearance, or correcting body odours, while maintaining the skin and its surrounding in good condition [11]. Nanomaterials can today be found in sunscreens, long-lasting makeup products (foundation, eye shadow), anti-ageing creams, toothpaste and haircare products to name just a few product types [12]. These products are thought to contain a variety of engineered nanomaterials ranging from metal oxides, fullerenes and quantum $\operatorname{dots}^{4}$ to liposomes and nanospheres [13]. Benefits of the use of nanomaterials in

3 The new industrial chemical regulatory regime established by REACH is characterised by a shifting of the burden of proof of safety away from the regulatory authorities to industry. This 180 degree shift has engendered significant debate in and beyond the EU in light of the onus, burden and costs placed on industry as a consequence of the regulation's entry into force.

4 Wilson F (2012) reports that quantum dots do not appear to have any utility in cosmetics and sunscreens. 
cosmetics range from enhanced formulation properties and acceptability, to greater sunscreening protection [8].

Nanomaterials are used in the manufacture of cosmetics in two important areas. One, as "encapsulation or carrier systems," to transport agents to deep skin layers where cell regeneration takes place, and as UV filters in sunscreens [14]. Nanocarriers, which do not possess any biological activity of their own, are employed to deliver vitamins, antioxidants, chemical UV filters, anti-acne or anti-aging substances into the target layers of the skin where they are dissolved and eroded [9]. Cosmetics are typically applied to the stratum corneum, the so-called horny layer-a layer of dead cells which functions to protect the body from the penetration of foreign substances including cosmetics [15]. Nanocarrier systems are used as a means of enabling cosmetic agents to penetrate into deeper skin layers where they activate skin metabolism with the aim of improving the appearance of the skin [14]. Liposomes, for example, are used primarily in cosmetics applications or for transdermal delivery with the expectation that their use will result in an increase in the concentration of active agents (including, for example, vitamins A, E and CoQ10) in the epidermis with no toxicity [16].

Globally, two metal oxide nanoparticles, titanium dioxide (TiO2) and zinc oxide $(\mathrm{ZnO})$ have been widely used as UV filters in sunscreens. ${ }^{5}$ These inorganic particles retain UV filtration and absorption properties, while eliminating the chalky white appearance of traditional sunscreens, thus enhancing cosmetic acceptability $[16,17]$.

While the use of engineered nanomaterials within cosmetics offers a range of benefits, there is increasing concern among some members of the scientific community regarding the possible adverse risks of certain families of nanomaterials, specifically insoluble and nonbiodegradable nanomaterials [18]. As Bowman et al. [19] note, such concerns are not unique to the cosmetics sector [20-22]. However, the direct application of cosmetic and personal care products onto the human body, along with the lack of certainty concerning the potential toxicity, fate and effect of some insoluble and/or non-biodegradable nanomaterials when placed on the skin, and the appropriateness of conventional risk assessment protocols has generated significant debate in the scientific and policy arenas [15,18,23,24,]. Definitive answers on safety still appear some time away, despite the increasing number of such products available on the market.

\section{But isn't Safety Assured? The Adoption and Implementation of the EU Cosmetics Regulation}

The adoption and entry into force of the Cosmetics Regulation ((EC) No 1223/2009) in 2013 replaced what had become "a patchwork of more than 45 amendments without coherent terminology" (EC, 2007, p: 2). The recast of the regime into one regulation was designed to promote legal clarity, and remove many of the legal uncertainties and inconsistencies that had underpinned the Cosmetic Directive and subsequent amendments. ${ }^{6}$ The regulation also introduces substantive changes, including an updatable glossary of cosmetics ingredients, safety assessment requirements, a strengthening of in-market controls and a product information file.

In addition to the general mandatory requirements of traceability, pre-market safety assessments, labelling, post-market surveillance and the elimination of animal testing, the regulation sets out an additional set of requirements for cosmetics products that contain 'nanomaterials'. For the purposes of the regulation, a 'nanomaterial' is defined so as to mean, 'an insoluble or bio persistent and intentionally manufactured material with one or more external dimensions or an internal structure, on the scale of 1 to $100 \mathrm{~nm}$...' (Article 2(k)).

As of July 2013, a responsible party planning to introduce a new cosmetic product containing nanomaterials into the EU market is required to supply safety information to the EC six months prior to its proposed release. For existing nano-based products (i.e., those that had been placed on the market prior to 11 July 2013), the Regulation requires that that the responsible party notify and provide safety data to the EC on the product (Article 16(3)). Should the Commission have concerns regarding the safety of the nanomaterial in a cosmetic product, they may request an opinion of the Scientific Committee on Consumer Safety (SCCS). The opinion must be made publically available (Article 16(4)).

Pursuant to Article 16(10)(a), the Regulation also requires the Commission to create, and publish, a catalogue of 'all nanomaterials used in cosmetic products placed on the market....and the reasonably foreseeable exposure conditions' by 11 January 2014. An 'annual status report' must be submitted by the Commission to the Parliament and Council on the 'developments in the use of nanomaterials' in the EU market (Article 16(10)(b)).

The Cosmetics Regulation stipulates that the manufacturer/ importer of cosmetics products containing nanomaterials must provide and communicate information to downstream users, that is, the consumer, in the form of a label. As noted in the Introduction, this must be indicated in the list of ingredients by placing the word 'nano' in brackets following the names of such materials (Article 19(1) (g)). The Regulation is silent on threshold limits concerning the nano label requirement. Thus, as Bowman et al. [2] observe, it would appear that even if nanomaterials are present only in trace amounts, a strict reading of the regulation would suggest that the labelling requirement is triggered.

The provision of additional information to all stakeholders is an important element in the thinking behind the regulation. This emphasis on the generation and disclosure of information can be attributed to the widespread knowledge gaps in the current state of the scientific-state-of-the-art; given epistemic limitations and the lack of concrete evidence that the use of nanotechnologies is likely to lead to unacceptably serious losses, legislatures have been inclined to view information regulation as a 'light touch' forerunner to potentially more restrictive forms of regulatory intervention (ibid).

5 In Europe currently, the use of $\mathrm{ZnO}$ as a UV filter (regardless of particle size) is only allowed in Germany, and not in the rest of the EU. Speaking of widespread use in this particular context, therefore, may be overstating the point, particularly when compared to $\mathrm{TiO}_{2}$, which is very widely used. (We are thankful to an industry respondent for providing this qualification.)

$6 \mathrm{http} / /$ www.europarl.europa.eu/sides/getDoc.do?pubRef=-//EP//NONSGML+IM-PRESS+20090323IPR52331+0+DOC+PDF+V0// EN\&language $=\mathrm{EN}$ 


\section{When is a nanomaterial not a nanomaterial for the purposes of regulation?}

The nano-specific requirements of the Cosmetics Regulation are only triggered when an ingredient falls within the nanomaterial definition as defined in the instrument itself. ${ }^{7}$ A number of observations can be made about the Cosmetic Regulation's definition of 'nanomaterial'; these observations offer an insight into the state-ofthe-art with regard to the use of nanomaterials in cosmetics and the perception of weaknesses/gaps in how the regulation deals with nanomaterials. First, according to this definition, particles which are soluble and intentionally manufactured but have one or more external dimensions or an internal structure on the scale from 1 to $100 \mathrm{~nm}$ will not be defined as a nanomaterial for the purposes of the regulation. As Bowman et al. observe [2], it is not surprising that the definition of nanomaterials adopted for the purposes of the Cosmetic Regulation excludes "soluble and/or biodegradable nanoparticles", focusing instead on "insoluble or biopersistent" nanoparticles, given that this differentiation between classes of nanomaterials was made by the Scientific Committee on Consumer Products (SCCP) (now the SCCS) in their 2007 Opinion on Safety of nanomaterials in Cosmetics Products. ${ }^{8}$ It was the Committee's opinion that the use or presence of insoluble or biopersistent nanoparticles in cosmetics regulation has the potential to raise more serious public health concerns should such particles penetrate the skin and pass into the vascular system. The European Consumers' Organisation (BEUC) has criticised the "narrowness" of this definition, voicing its concern that certain nanomaterials-in this case, soluble nanomaterials-escape the requirements of the regulation [25]. Second, insoluble or biopersistent and intentionally manufactured particles which do not have any dimensions or an internal structure of $1-100 \mathrm{~nm}$, but may have a dimension of $101 \mathrm{~nm}$ and exhibit the same functionality or novelty, will also not be defined as a nanomaterial for the purposes of the regulation even though there is no scientific evidence to support the appropriateness of this value [26,27]. While the thresholds chosen reflect political compromises and practicality, there is nonetheless the potential that different-and potentially hazardous-properties may also arise for a specific material at sizes above $100 \mathrm{~nm}$ [28]. Third, the definition used in the regulation does not make reference to the need for 'special' or 'unique' properties to be displayed within the defined size range. This is despite the fact that the main safety concerns relating to nanomaterials concern size, in addition to surface area and surface reactivity [29].

Given that the science is moving at a rapid pace, the Regulation recognises the need to adapt the definition in line with scientific and technological developments and definitions subsequently agreed at international level (Article 2(3); see also Preamble, at 29). In October 2011, the EC published a 'Recommendation on the definition of a nanomaterial', primarily intended to offer a common understanding of the term "nanomaterial" so as to avoid confusion regarding terminology and inconsistency between different pieces of legislation. ${ }^{9}$ The definition adopted by the Council and Parliament in the Cosmetic Regulation differs from that adopted by the EC (2011), and the European Parliament and Council for the purposes of the Food Labelling Regulation. As such, what is meant by a 'nanomaterial' within the EU may have multiple answers, and shall give rise to different regulatory approaches between the various market sectors. ${ }^{10}$

\section{Labelling as an information disclosure tool: a variety of meanings and perceptions}

Policy makers and regulators currently face a significant challenge in finding an appropriate balance between consumer protection-given myriad uncertainties concerning risk assessment of nanomaterialsand industrial competitiveness [31]. While the nano-specific provisions in the Regulation can be seen as a response to political concerns about transparency and the need for consumer protection, these provisions do, of course, have potentially far-reaching effects in practice, for companies and the consumer, within, and beyond, the EU's borders.

The focus of this article is the introduction and operation of nanospecific provisions and the shift in responsibilities created by the Cosmetic Regulation. The introduction of information disclosure mechanisms geared towards transparency means that consumers now have a role in the regulation of nanotechnologies. Specifically, the labelling tool is meant to facilitate consumers' enactment of responsibility. However, as already outlined in the Introduction, uncertainty as to the meaning of the label and the extent to which it allows the consumer to make a fully informed choice underline attendant problems in this shifting of responsibilities. In order to have some understanding of the challenge of shifting responsibilities to the consumer, it is necessary to take a closer look at the 'nano' label in relation to what it is meant to denote, in addition to varying perceptions of the potential meaning attached to the label in policy discourse and on the part of the consumer.

Labelling as an information disclosure tool fulfills a transparency function in terms of the "provision of information to consumers on the use of nanomaterials in consumer products" [32]. Labelling thereby, in this situation, can be seen as facilitating the consumer's right to know what they are putting on their skin, and facilitates the right to choose between materially different products [7]. Yet, the proposed labelling of products containing nanomaterials is a highly sensitive and contested area [33]. Proponents point to the contribution of labelling to building trust among stakeholders and helping to establish the "social legitimacy" of the technology [34]; opponents

\footnotetext{
7 Given the fact that the inclusion of nanospecific provisions creates further legal obligations for responsible parties, it will be the decision of the producer/manufacturer as to whether they want to offer a product incorporating nanomaterials $[2,6]$. Moreover, if a current product containing nanomaterials can be reformulated so as to retain the same functionality without the inclusion of nanomaterials, and it is economical to do so, some companies may replace nanomaterials with larger particles so as to avoid triggering the additional set of (nano) requirements [2]. Such a decision shall no doubt be made on a case-by-case basis by the responsible party/ies.

$8 \mathrm{http}: / /$ ec.europa.eu/health/ph_risk/committees/04_sccp/docs/sccp_o_123.pdf

9 http://ec.europa.eu/environment/chemicals/nanotech/

10 Issues surrounding the appropriateness of the definition of 'nanomaterial'-albeit the EC's definition, or the two different definitions now in place in legislation-and threshold limits serve to underline the place of somewhat arbitrary and political choices as opposed to purely science based decisions in the making of health and safety legislation [23,28]. For Hodge et al. [30], the adoption of three different definitions for a nanomaterial by the Commission and the Parliament, and the passage of the two regulatory instruments in the absence of definitive scientific harm, is illustrative of the inherent political nature of regulation/legislation.
} 
observe that such labelling regimes do not inform the user about the specific risks, if any, of the technology/nanomaterials [35]. Opponents also note that such a label may also be perceived as a hazard or warning label, despite inconclusive scientific data on potential risks.

But how do key stakeholders, including government and industry view the regulation and its nano-specific requirements? It is to this issue that this article now turns.

\section{Findings: Stakeholders' Views of the Cosmetics Regulation, Nano-specific Provisions and Regulatory Obligations}

\section{Method}

The authors conducted 16 semi-structured interviews with representatives from government (including regulatory agencies), industry, non-governmental organisations (NGOs), and experts (in toxicology/industry, and dialogue) between July 2012 and August 2013. Respondents were located in the Netherlands $(n=5)$, Belgium $(n=6)$, the UK $(n=3)$ and Germany $(n=2)$. The majority of interviews were undertaken in a face-to-face setting $(n=9)$, with the exception of those with stakeholders located in the UK and Germany, and one in the Netherlands $(n=7)$. Interviews ran for between 30 minutes and 45 minutes.

Respondents were selected on the basis of purposive sampling, i.e. respondents were selected with a purpose to represent a particular type of stakeholder-industry, government/regulatory agency, NGO/civil society, academic/expert in their field-in relation to their having a stake in nano-cosmetics and the nano-specific provisions of the regulation or having a clear stakeholder perspective on the regulation and nano-cosmetics more generally. The selection of first-round interviewees was based on the insights and expert knowledge of a colleague who had been involved in public dialogue activities, one of which centred on nano-cosmetics. The selection of second-round interviewees was based on the authors' identification of stakeholders encountered in researching nano-cosmetics and the new regulatory regime.

Interviewees were asked questions relating to their views of the new regulation, including the benefits/challenges of the regulation, their views concerning the obligation put on producers and importers of cosmetic products, the preparations they were undertaking in order to ensure enforcement/compliance, their views on the distribution of regulatory responsibilities implied by the regulation, and views regarding the nano label and the message it conveys (see Appendix 1 for the interview instrument).

While a small number of interviews were carried out, they nonetheless encompassed a range of stakeholder groups, expertise and views. However, given the small number of interviews, it is only possible to identify themes across the interviews; it is not possible to make any general conclusions as to the findings. Moreover, the interviews represented actors within a very narrowly defined jurisdictional area, implying limitations with regard to an allencompassing description of stakeholder perspectives on the new regulatory regime.

\section{Views of the cosmetic regulation}

The initial question posed to the sixteen respondents focused on eliciting their views on the new regulatory regime generally. Despite the overarching nature of the question, nearly all of the respondents focused almost immediately on the nano-specific provisions, including issues relating to transparency and safety.

The facilitation of enhanced safety was similarly viewed as an improvement by some stakeholders, but in particular by those within government/regulatory agencies $(\mathrm{n}=2)$. Indeed, Respondent $\mathrm{A}$ (national regulatory authority representative) welcomed the enhanced disclosure requirements for nanomaterials, as they perceived the need for regulatory authorities to know when nanomaterials are being used in order to check "uncertainties in the safety area". Respondent B (regulatory agency representative) referred to the benefits of the regime as "the fact that we will know very clearly what will be on the market, what's on the market and we will have a chance in case of doubts regarding the safety to double check". This was, in their view, further reinforced by the "additional guarantee", i.e., that a second assessment of safety by the Scientific Committee on Consumer Safety (SCCS) may be carried out in the event that the Commission requires an ad hoc evaluation of a specific substance in the form of a nanomaterial.

Some of the respondents representing industry $(n=2)$, focused in on the elements of the regulation which function to facilitate greater transparency. While viewed as positive by one industry respondent (Res. C, national industry association representative), due to the perceived importance of enhanced transparency for industry, another industry representative viewed the requirements more generally within the framing of the political heritage of the nano-specific provisions in the regulation. For Res. D (national industry and employers' association representative), the Cosmetics Regulation is best considered as a consumer regulation which can be used to "satisfy the public debate" and to circumvent the "risk that politicians will say "No, no nanoparticles in cosmetics products in Europe because we don't know (the risk)"."

Such sentiments were echoed by Respondent E (NGO representative), representing an environmental NGO, who, while stating that they believed that the regulation was a step in a positive direction, commented that it was "not really solving the problem", given issues concerning the definition of nanomaterials and a lack of standardised methodologies for risk assessment.

Other, more general, perceived benefits of the new regime for respondents included enhanced market surveillance and harmonisation between Member States and centralization of certain administrative functions (Res. G, European industry association representative); and enhanced product safety and the reduction of misleading claims (Res. F European consumer organisation representative).

\section{Preparing for the new regulation}

When asked about how their organisations were preparing for the new regulation, respondents offered a range of views. For industry representatives, preparations included data gathering activities for the purposes of informing the public about the meaning of the label; regulatory agencies were concerned with putting the necessary tools in place; and consumer organisations were focused on preparing the necessary resources to provide input to the regulator.

In outlining the preparations that industry needs to undertake, Res. C (national industry association representative) focused in on the notification requirements, which would involve significant cost and time, in addition to an active role for his organisation in informing the 
public that the label indicates the presence of a nano ingredient in the product and "has no meaning at all" as to the safety or use of the product. Res. H (European industry association representative) referred to the challenge faced by industry regarding the correct characterisation of ingredients as nanomaterials.

Somewhat surprisingly, given the general call made by NGOs to be involved at an early stage of the innovation process, the NGOs (specifically Res. E and Res. K) were rather reticent about any activities they might pursue in preparation for the regulation.

\section{View of obligations}

Not surprisingly, when asked about their views of the obligations created by the regulation, positions varied depending on the respondent's background with some respondents Res. C (national industry association representative) and Res. A (national regulatory authority representative) suggesting that the responsibilities on the various parties are straightforward, through to being more complex in nature, and involving multiple strands.

Res. D (national industry and employers' association representative) was satisfied overall with the regulation, particularly with the consumer element, as the organisation that they represent is concerned with the overall reputation of industry. Of importance to them, therefore, is the avoidance of a moratorium on the use of nanomaterials in products.

More critical views of the obligations were put forward by those representing consumers, particularly given the nature of the products, i.e., ones that are designed to be directly applied to, or to come into contact with, the body. Concern that the regulation is not satisfactory from the point of view of allowing the consumer to make an informed choice was once again expressed by Res. E (NGO representative). This position was further elaborated on, with reference to both the labelling mechanism and the publically available catalogue of nanomaterials:

So, I don't see consumers going to the shop, looking at the ingredients list, seeing that product contain nanoparticles, going home or surfing to (the publically available catalogue) on their phone, checking out what kind of particles these are and then trying to inform themselves about the potential risks of such particles. So, it's gonna be very hard for people to make an informed choice. It's not enough in that sense.

Res. K (NGO representative) expressed their concern over the accessibility of the publically available catalogue of nanomaterials. According to Res. B (regulatory agency representative), the public shall be made aware of the existence of the catalogue of nanomaterials through a number of mechanisms including a publication on their website, through relevant associations, and other stakeholder groups.

Are the obligations on industry satisfactory? The regulatory text "is not bad", according to Res. F (European consumer organisation representative), with the bigger tests being in relation to the day-today operation of the regulation and its implementation at national level. Res. O (industry expert) felt that the ultimate test of the regulation shall be whether it effectively serves the consumer, industry and government once implemented.

\section{Fairness of the distribution of responsibilities}

The perceived distribution of responsibilities between the various parties, and the 'fairness' of such was also of interest to the authors.
For the purposes of the interviews and the study more generally, fairness was defined as the distribution of responsibilities in such a way that those in a weaker position, such as consumers, are given responsibilities that they do not have the tools or capacity to knowingly bear.

According to Res. A (national regulatory authority representative), the distribution of responsibilities is fair in that the responsibility for knowledge of ingredients and labelling-and safety-rests with the producer, while the labelling mechanism operates to give consumers freedom of choice over the purchase and/or use of such products. Res. $\mathrm{G}$ (European industry association representative) articulated a similar view in relation to the label.

A clear division in views of fairness existed among the other respondents. Res. D (national industry and employers' association representative), for example, was satisfied with the obligations, explaining that the regulation offers a means for industry to satisfy the public debate and is "livable and manageable". Res. J (chemical manufacturers' association representative), similarly speaking from an industry perspective, felt that the producer will be of the view that they have done everything they can for the consumer, and argued that the consumer must be able to do something with the label.

This argument, about consumers' capacity to do something with the label, was at the crux of the matter for the NGO respondents. Res. E (NGO representative) felt that-based on the information provided from July 2013 when the regulation was to come into force-it is not fair to place responsibility on the consumer. This view was shared by Res. K (NGO representative). Res. P (representative of national organisation representing interests of consumers and users) took a slightly different view, asserting that fairness depends on the degree of uncertainty. He offered two reasons for this assertion: first, tests usually show nanomaterials to be safe and; second, since the uncertainty has not been "filled in", in the sense that the danger is tangible or visible, it is fair to place part of the "burden of uncertainty" on the consumer.

Res. F (European consumer organisation representative) spoke about the importance of the different responsibilities fitting together. Consumers, she said, should never have to choose between unsafe or safe products as, by law, all consumer products on the market have to be safe. In the first instance, it is the manufacturer's responsibility to ensure full product safety. The regulator has to make sure that the rules for safety are put in place and that these are sound and sufficient. Market surveillance authorities have an obligation to enforce the legal rules and to make sure that there are no dangerous products on the market. Res. F felt that, while there are some good provisions in the cosmetics regulation concerning nanomaterials, certain concepts, e.g. the definition of 'nanomaterials' in the regulation, are still not clear. She concluded by saying that without clear legal rules and a lack of adequate human and financial resources with which to carry out market surveillance, full safety for consumers is currently not ensured.

Such sentiments were echoed by Res. M (Member of European Parliament), who felt that labelling-and the implied distribution of responsibility to the consumer-is the "second-best solution". In their view:

"Ideally, we would ban all nanoparticles that are not proven safe when you put them on your skin-I think that's a reasonable approach but we didn't take that responsibility so we put that responsibility on the consumer to make it voluntary to avoid it and of course that's not optimal." 
Such opinions stand in stark contrast to those elicited from those representing industry, and, to a lesser degree, those representing CSOs.

\section{The 'nano' label}

Respondents were largely in agreement regarding the role, and meaning, of the 'nano' label. The view put forward by Res. A (national regulatory authority representative) that, “...it's not the intention that the consumer does anything with it, but some consumers will use it in their decision-making", was echoed to varying degrees by other respondents. There was, however, very little consensus on all other aspects of the nano label.

For example, some respondents (Res. E (NGO representative); Res. $\mathrm{K}$ (NGO representative); and Res. L (dialogue expert) were critical of the requirement to insert 'nano' into the ingredients list, given their conviction that many consumers-notwithstanding those more active consumers (in the minority) who are willing to make the effort to read the ingredient list and get confirmation of the presence of nanomaterials-will not bother to look at the label. Even when the consumer does engage with the label, a number of respondents felt that it would only be useful to a minority of consumers.

Others felt differently. For four respondents, despite their view that the label does not convey any message, they felt that the public may nonetheless interpret the label as something negative. Given the low consumer awareness of nanotechnologies, there was concern that people may try to infer what they think is the implicit message of the label such that labelling may be taken up as a negative, warning sign indicating risks associated with the technology, notwithstanding the fact that there may be no evidence suggesting such risks do indeed exist.

In contrast, Res. F (European consumer organisation representative), felt that "putting (nano) in brackets in the list of ingredients is a very good way of communicating to consumers because it's not evaluating the information-it's neutral information-so it doesn't tell people "do not buy this product" (...)-it leaves the decision to the consumers (...)". In their view, such information allowed for informed choice; this was despite the fact that the lack of a valid definition may imply a period of uncertainty or misinformation to the consumer.

This view stands in stark contrast to those of Res. E and K (both NGO representatives) and L (dialogue expert), each of whom stressed the need for additional information to be provided alongside the label; for them, consumers needed something more given that the label itself does not speak to the nature, function or benefits (or potential risks) of the 'nano' ingredient in the product. These respondents stressed the need for informed choice. Informed choice, as articulated by Res. K, would require significant additional research into safety assessments. Such views were similarly echoed by Res. J (chemical manufacturers' association representative), who asserted that in order to understand the message of the label, the consumer should have a minimum understanding of the natural sciences and understand the nano label as information regarding scale.

Those representing various publics, specifically Res. F (European consumer organisation representative) and Res. M (Member of European Parliament), were largely satisfied with the labelling mechanism. However, both believed that the definition of a 'nanomaterial' should be revised so as to be consistent with that of the EC.
But what about the issue of transparency? Does the employment of a nano label promote transparency in the market place? For some, the answer was a clear and unambiguous 'yes'. For example, Res. B (regulatory agency representative) was satisfied that labelling-in addition to the catalogue of nanomaterials used in cosmetic products and the Commission's annual status reports on developments-offers the most effective means of facilitating transparency in terms of "knowing what is out there and in which kinds of products". Res. N (NGO representative) viewed labelling primarily as a kind of procedural formality, so that "companies know that somebody cares about how they do things".

\section{Additional regulatory challenges}

Additional regulatory challenges were readily identified by a number of respondents, and included issues pertaining to the applicability of standardised risk assessment models for specific families of nanoparticles. Res. B (regulatory agency representative), in particular, zeroed in on the importance of analytical methods with which to accurately characterise nanomaterials for enforcement. For them,

“(...) methods that allows the detection of nanomaterials in the finished product (are of great concern to the competent authorities) because once you have rules, you also need the tools to check that the rules are being respected (...)".

Res. B went on to speak about the need for the Commission to prepare guidance on the application of the definition of nanomaterials. Yet, the initial absence of such guidance should not, in their view, be problematic if industry has "done their homework regarding how to work with the definition".

Enforcement and compliance were similarly identified by several respondents as potential regulatory challenges in the short to medium term. Res. A (national regulatory authority representative) suggested that enforcement by the regulatory authority is most likely, at least in the first phase, to focus on the product dossiers. The difficulties industry faces regarding the provision of safety data were identified by Res. C (national industry association representative) as a significant challenge for compliance. In their words, "getting data is, I think, one of the most difficult items in our industry". He went on to explain that if materials sellers want to sell materials to the cosmetics industry, they also have to contribute to getting the data; or they have do it themselves for registration with REACH or other regulatory systems; or they have to make an agreement as to how and where to carry out studies to get the data. By contrast, industry respondents involved in the manufacturing of specific nanomaterials (Res. I and J) reported that they did not face challenges, given their understanding that $\mathrm{TiO} 2$ is safe and ultrafine $\mathrm{TiO}_{2}$ is on the positive list of substances for the $\mathrm{REACH}$ regulation.

\section{Threads and themes: the challenge of distributing regulatory responsibilities}

The challenge of distributing regulatory responsibilities for unknown, unquantifiable, or indeed simply perceived, risks in terms of the provision of information down the value chain was viewed quite differently by industry stakeholders and regulatory authorities, on the one hand, and CSOs, on the other. Respondents from the regulatory authorities appeared to be satisfied, overall, that the enhanced notification requirements would enable them to check uncertainties concerning safety, along with the "additional guarantee" facilitated by 
the second assessment of safety by the SCCS (if required). Those from industry felt their responsibilities were very clear: the responsible person has responsibility for the safety of the product and for knowledge of ingredients and must fulfill notification and labelling requirements. Notwithstanding the challenge of obtaining safety data (particularly for small companies) and the added administrative burden of the notification of data and requirement to label, the obligation put on producers and importers of cosmetics products was accepted as sufficient.

A number of respondents representing the interests of civil society, however, did not view responsibilities in such a straightforward way. These respondents felt that, given that the consumer takes part in risk assessment and management through their purchasing decisions, the distribution of regulatory responsibilities across the value chain does not suffice to allow the consumer to enact their responsibility to choose between products that do or do not contain nanomaterials. This can be contrasted with industry views, with Res. G (European industry association representative) suggesting that the shifting of some responsibility to the consumer is fair within the purposes of the label, i.e. to provide information regarding the presence of nanomaterials in the product.

As we noted in Section 3, the label has a transparency function in terms of enabling consumers' right to know what they are putting on their skin, in addition to the right to choose between materially different products. However, as one respondent from civil society observed, there appears to be a degree of incongruence between the transparency aim of the label and enabling genuine consumer choice. Res. E (European consumer organisation representative) felt that the nano label is very limited in terms of facilitating genuine, informed consumer choice, while the nano label allows the consumer to establish that there are nanomaterials in the product, they require additional safety information in order to make a fully informed choice. Indeed, two of the industry respondents (Res. $\mathrm{H}$ and $\mathrm{J}$ ) referred to the need for the consumer to have some level of awareness that the nano label provides information regarding scale. In terms of consumers acquiring the necessary knowledge regarding the different types of nanomaterials being incorporated into cosmetic products and additional safety information, two civil society respondents -Res. E and $\mathrm{K}$-had doubts regarding the visibility of the publically available catalogue of nanomaterials, and whether consumers would even use it.

\section{Moving Forward}

In this article, we used the lens of the regulation of cosmetics products in the EU from July 2013 onward in order to understand the challenge of distributing regulatory responsibilities for unknown and unquantified risks relating to the use of nanomaterials in cosmetic products. While there has been much written on the use of nanomaterials in personal care products, medicines and foods, for example, the reality of their use, challenges and tensions, remainsstill-somewhat opaque. The findings presented in this article, drawn from a small number of interviews, underscore the very real difficulties and tensions that have arisen, and shall continue to arise, when information disclosure tools such as labelling and the publically available catalogue of nanomaterials lie at a confluence between scientific uncertainty, on the one hand, and consumer protection, on the other.

The provision of information, as noted already, is a relatively mild regulatory tool, but shall, in our view, have important effects in practice. The provision of information via the mandated labelling requirement places considerable obligations on the responsible persons, the fulfillment of which is far from straightforward. In addition, the label conveys different meanings to different actors, and importantly, makes it difficult for the consumer to enact their responsibility in the regulation of nanotechnologies. Even now, following the implementation of the regulation, it is still unclear how this division shall occur.

In this article, responsibility of the consumer was framed in terms of their being able to differentiate between materially different products and making a genuinely informed choice. As the regulation was only implemented in July 2013, much has to be seen with regards to how the regulation and the nano-specific provisions will be applied in practice. However, we can already zoom in on the various components of the regulatory framework for nanomaterials that warrant further attention so as to allow the enhanced functioning of labelling mechanisms and to enable the enactment of consumer responsibility.

First, there is the challenge concerning the characterisation/ definition of nanomaterials. The effectiveness of the regulation is fundamentally dependent on industry being able to accurately characterise ingredients as 'nanomaterials', as defined in the regulation, in order to be able to comply with the labelling requirement. This is certainly not an easy task and definitional issues shall be key here, especially given the variation in definitions that exist between the instrument and the EC's own definition. To assist with this, the Commission is preparing guidance on implementation of the EC definition. However, until such guidance is issued, all actors across the value chain-regulators, industry, business operators and consumers-face a period of uncertainty. Such complexities are further exacerbated by the fact that, as of August 2013, three EU regulations contain different definitions of nanomaterials (the Biocidal Products regulation largely incorporates the definition of nanomaterials from the 2011 EC Recommendation on nanomaterials). As a number of commentators have observed [28,36,37], differentiation in the definition of nanomaterials, e.g., with regard to natural, incidental and manufactured nanomaterials, and soluble versus non-soluble, and so on, may be necessary and/or relevant given strong divergences in the application of nanomaterials. However, such differentiation will have important effects in practice. Bowman et al. [2] have suggested, for example, that manufacturers and/or importers with nanotechnologybased product lines in both the cosmetics and food sectors within the EU will have to ensure that they are aware of the varying definitions and attendant regulatory implications in order to ensure compliance.

Differentiation of terminology will also have effects in practice for the consumer. This brings us to a second challenge: different nano labels will not be crafted using the same definitional foundations, further complexifying the landscape for consumers. While a model for labelling in the EU has been established, in the sense that the nanospecific provisions in question are the same, i.e., nanomaterials must be labelled and the word 'nano' added in brackets (cf. [36]), differences in the definition of nanomaterials in one product sector or area of regulation will have implications for how nano-labels in very different sectors are read by the consumer. The possibility for confusion is most notable for the labelling obligation for biocidal products which stipulates that "any specific related risks" (Article 69(2)(b)) in biocidal products containing nanomaterials should be identified. If this risk identification element of labelling-in place only for the biocidal products regulation-were to enter into the public domain around the 
same time that consumers become aware of the nano label in the cosmetics and/or food sectors, the consequences for nanocommercialisation and further investment in nanotechnologies could be significant.

So where to from here? In our view, there is an imperative for the EC to take the necessary actions to ensure a timely and smooth implementation of the regulation, and all its various parts. This includes providing the necessary guidelines and guidance documents for industry, including those relating to measurement, characterization, testing methodologies and definitional issues.

The provision of such information is crucial and directly impacts on the commercialization of products containing nanomaterials. It also goes to the heart of ensuring that consumers have access to balanced and factual consumer knowledge of nano-based products. Moreover, we would argue that the more timely such information is made available, the better the chance to disentangle the (perceived) risk and safety aspects of nanomaterials from the risk and safety aspects of nano-enabled products within the EU market.

We would also argue that with the regulation now in effect, there is an urgent need for balanced information campaigns to be launched in all member states; accessible campaigns should complement the disclosure tools found in the Cosmetic Regulation, and seek to enhance the overall information exchange associated with its implementation. Although the publically available catalogue of nanomaterials shall implicitly function as a complement to the labelling mechanism, it appears unlikely-as suggested by our respondents-that consumers would, in the first instance, be aware of the existence of such a catalogue, and second, take the time and effort to consult the catalogue. As such, something additional that enhances accessibility is needed. For these reasons, along with inherent scientific and technical uncertainties, it seems imperative that information campaigns should take place in parallel with the labelling mechanism on nano-cosmetic products. Information campaigns should be balanced, expanding on both the perceived benefits and risks of such products.

The use of a nano label for cosmetic products within the EU market is now a reality. ${ }^{11}$ Importantly, the introduction of a nano label in itself is not, at least in our view, a means to an end. In its current form it does not suggest potential risks, nor does it guarantee safety. There is much more work that needs to be done, and eliciting the views of expert stakeholders within the arena shall be fundamental to striking an appropriate balance in the short and medium term.

\section{Appendix}

Interview instrument: the following questions were addressed to some respondents and were re-framed or supplemented in other cases, according to the particular stakeholder to be interviewed

- What is the respondent's view of the new Cosmetics Regulation?

- What are the benefits/challenges of the new regime? Do they think the new regulation was warranted? Does the new regulation increase/decrease their regulatory burden? Costs, etc.? How does the notification requirement compare to the new regulation more generally?
- Are they satisfied with the obligation put on producers and importers of cosmetic products?

If not, why not?

What are the views of their members?

Can they think of alternatives?

- Need to understand who the market is for industry actors: Are they selling into the EU market? Do they have compliance issues that extend beyond the EU market? (This is likely to impact how they see the new regime)

- Do they face challenges regarding the provision of safety data?

- How is the organisation preparing for the new regulation?

- Questions regarding enforcement and compliance. How should this be done? Is it achievable? What are the practical limits of enforcement? What are the penalties for non-compliance (what are the risks, in their view, of actually getting caught for noncompliance?)

- Do they envision problems in the application (use) of the new regulation with regard to the distribution of responsibilities?

- Do they think that the distribution of responsibilities implied by the new regulation is fair or not?

By 'fair', I mean that responsibilities are distributed in such a way that those in a weaker position are protected (the stronger party should be able to provide information in order that the weaker party can make a claim) and not given a responsibility they are unable to assume, e.g. think about the burden of proof on the consumer

- Do they see any additional regulatory problems?

Lack of expertise on the part of regulators; related problems of regulatory capacity

- What does the 'nano' label mean to the respondent/organisation?

- In the respondent's view, what kind of message does the nano label convey to the consumer?

What does this understanding mean for the distribution of responsibilities?

- Can the respondent suggest alternatives for labelling?

- Ask industry actors if they have voluntarily labelled products already? If so, why?

Reformulation of ingredients so as to exclude an unnecessary nanovariant and avoid the stigma attached to the label: ask industry actors if this is part of their plan/approach to dealing with the regulation?

\section{References}

1. Breggin L, Falkner R, Jaspers J, Pendergrass J, Porter R (2009) Securing the Promise of Nanotechnologies: Towards Transatlantic Regulatory Cooperation. Chatham House, London.

2. Bowman DM, van Calster G, Friedrichs S (2010) Nanomaterials and regulation of cosmetics. Nat Nanotechnol 5: 92.

3. Hansen SF, Baun A (2012) European regulation affecting nanomaterials review of limitations and future recommendations. Dose Response 10: 364-383.

4. Moore J1 (2012) New Zealand's regulation of cosmetic products containing nanomaterials. J Bioeth Inq 9: 185-188.

11 This action by the Parliament and Council highlights the political nature of rule making, and the role that government plays in shaping and changing behavior. 
Citation: Shelley-Egan C, Bowman DM (2015) The Challenge of Distributing Regulatory Responsibilities for Unknown Risks: 'Nano'-Cosmetics and the EU Cosmetics Regulation as a Case Study. J Clinic Res Bioeth 6: 212. doi:10.4172/2155-9627.1000212

Page 10 of 10

5. Bowman DM, Ludlow K (2013) "Assessing the impact of a 'for government' review on the nanotechnology regulatory landscape." Monash Law Journal 38: 168-212.

6. Throne-Holst H, Rip A (2011) Complexities of labelling of nanoproducts on the consumer markets. European Journal of Law \& Technology 2: 1-12.

7. Stokes E (2011) You are what you eat: market citizens and the right to know about nano foods. Journal of Human Rights and the Environment 2: $178-200$.

8. Wilson RF (2012) Enlarging the Regulation of Shrinking Cosmetics and Sunscreens. In: Dana DA (ed), The Nanotechnology Challenge: Creating Law and Legal Institutions for Uncertain Risks. Cambridge University Press, pp: 250-308.

9. Mihranyan A, Ferraz N, Stromme M (2012) Current status and future prospects of nanotechnology in cosmetics. Progress in Materials Science 57: 875-910.

10. Which? (2008) Small Wonder? Nanotechnology and Cosmetics: Briefing. Which?, London.

11. Morganti P (2010) Use and potential of nanotechnology in cosmetic dermatology. Clin Cosmet Investig Dermatol 3: 5-13.

12. IRGC (2008) Risk Governance of Nanotechnology Applications in Food and Cosmetics. International Risk Governance Council, Geneva.

13. Friends of the Earth (2006) Nanomaterials, sunscreens and cosmetics: Small ingredients, big risks. Melbourne, Friends of the Earth Australia and the United States.

14. Grebler S, Gazso A, Simkó M, Fiedeler U, Nentwich M (2010) Nanotechnology in Cosmetics. Nano Trust-Dossier No. 008en.

15. Hoet PH, Brüske-Hohlfeld I, Salata OV (2004) Nanoparticles - known and unknown health risks. J Nanobiotechnology 2: 12.

16. Mu L, Sprando RL (2010) Application of nanotechnology in cosmetics. Pharm Res 27: 1746-1749.

17. Cross SE, Innes B, Roberts MS, Tsuzuki T, Robertson TA, et al. (2007) Human skin penetration of sunscreen nanoparticles: in-vitro assessment of a novel micronized zinc oxide formulation. Skin Pharmacol Physiol 20: $148-154$.

18. Scientific Committee on Consumer Products (2007) Opinion on Safety of Nanomaterials in Cosmetics. European Commission, Brussels.

19. Bowman DM, van Calster G (2008) "Flawless or Fallible? A Review of the Applicability of the European Union's Cosmetics Directive in Relation to Nano-Cosmetics." Studies in Ethics, Law, and Technology 2.

20. Colvin VL (2003) The potential environmental impact of engineered nanomaterials. Nat Biotechnol 21: 1166-1170.

21. Handy RD, Owen R, Valsami-Jones E (2008) The ecotoxicology of nanoparticles and nanomaterials: current status, knowledge gaps, challenges, and future needs. Ecotoxicology 17: 315-325.
22. Choi JY, Ramachandran G, Kandlikar M (2009) The impact of toxicity testing costs on nanomaterial regulation. Environ Sci Technol 43: 3030-3034.

23. Maynard AD1 (2007) Nanotechnology: the next big thing, or much ado about nothing? Ann Occup Hyg 51: 1-12.

24. Nel A, Xia T, Mädler L, Li N (2006) Toxic potential of materials at the nanolevel. Science 311: 622-627.

25. Montague-Jones G (2009) New EU rules on nanomaterials cause controversy.

26. European Commission (2011), Commission Recommendation of 18 October 2011 on the definition of nanomaterial (2011/696/EU). European Commission, Brussels.

27. Scientific Committee on Emerging and Newly Identified Health Risks (2010) Opinion on Scientific Basis for the Definition of the Term "nanomaterial". European Commission, Brussels.

28. Bleeker EA, de Jong WH, Geertsma RE, Groenewold M, Heugens EH, et al. (2013) Considerations on the EU definition of a nanomaterial: science to support policy making. Regul Toxicol Pharmacol 65: 119-125.

29. Henkler F, Tralau T, Tentschert J, Kneuer C, Haase A, et al. (2012) Risk assessment of nanomaterials in cosmetics: a European union perspective. Arch Toxicol 86: 1641-1646.

30. Hodge GA, Maynard AD, Bowman DM (2013) Nanotechnology: Rhetoric, risk and regulation. Science and Public Policy sct029.

31. Gergely A, Coroyannakis L (2009) Nanotechnology in the EU cosmetics regulation. Household and Personal Care TODAY 3: 28-30.

32. European Parliament (2009) Report on regulatory aspects of nanomaterials (2008/2208 (INI)). European Parliament, Brussels.

33. D'Silva J, Bowman DM (2010) “ To Label or Not to Label? - It's More than a Nano-sized Question.” The European Journal of Risk Regulation 4: 420-427.

34. Gruère GP (2011) Labeling nano-enabled consumer products. NanoToday 6: 117-121.

35. Breggin L, Falkner R, Jaspers J, Pendergrass J, Porter R (2009), Consumer Labelling of Nanomaterials in the EU and US: Convergence or Divergence? EERG Briefing Paper 2009/03. Chatham House, London.

36. Eisenberger I, Grebler S, Nentwich M (2012) On voluntary and obligatory nano-labelling. NanoTrust-Dossier No. $031 \mathrm{en.}$

37. Rauscher H, Sokull-Klüttgen B, Stamm H (2013) The European Commission's recommendation on the definition of nanomaterial makes an impact. Nanotoxicology 7: 1195-1197. 